\title{
Hydrogen sulfide-releasing cyclooxygenase inhibitor ATB-346 enhances motor function and reduces cortical lesion volume following traumatic brain injury in mice
}

Michela Campolo ${ }^{1 \dagger}$, Emanuela Esposito ${ }^{1 \dagger}$, Akbar Ahmad ${ }^{1}$, Rosanna Di Paola ${ }^{1}$, Irene Paterniti ${ }^{1}$, Marika Cordaro ${ }^{1}$, Giuseppe Bruschetta ${ }^{1}$, John L Wallace ${ }^{2}$ and Salvatore Cuzzocrea ${ }^{1,3^{*}}$

\begin{abstract}
Background: Traumatic brain injury (TBI) induces secondary injury mechanisms, including dynamic interplay between ischemic, inflammatory and cytotoxic processes. We recently reported that administration of ATB-346 (2-(6-methoxynapthalen- 2-yl)-propionic acid 4-thiocarbamoyl-phenyl ester), a hydrogen sulfide-releasing cyclooxygenase inhibitor, showed marked beneficial effects in an animal model of spinal cord injury, significantly enhancing recovery of motor function and reducing the secondary inflammation and tissue injury.

Methods: Here we evaluated the neuroprotective potential of ATB-346, a hydrogen sulfide-releasing derivative of naproxen, using the controlled cortical impact (CCI) injury model in mice, one of the most common models of TBI. Moreover, the aim of the present study was to carefully investigate molecular pathways and subtypes of glial cells involved in the protective effect of ATB-346 on inflammatory reaction associated with an experimental model of TBI. In these studies, TBI was induced in mice by CCI and mice were orally administered ATB-346, naproxen (both at $30 \mu \mathrm{mol} / \mathrm{kg}$ ) or vehicle (dimethylsulfoxide:1\% carboxymethylcellulose [5:95] suspension) one and six hours after brain trauma and once daily for 10 days.

Results: Results revealed that ATB-346 attenuated TBI-induced brain edema, suppressed TBI-induced neural cell death and improved neurological function. ATB-346 also significantly reduced the severity of inflammation and restored neurotrophic factors that characterized the secondary events of TBI.

Conclusions: These data demonstrate that ATB-346 can be efficacious in a TBI animal model by reducing the secondary inflammation and tissue injury. Therefore, ATB-346 could represent an interesting approach for the management of secondary damage following CNS diseases, counteracting behavioral changes and inflammatory process.
\end{abstract}

Keywords: Brain trauma, Hydrogen sulfide, Neurotrophic factor, Inflammation, Motor recovery, Infarct area, Infarct volume, Nitrosative stress, Astrogliosis, Neuroprotection

\footnotetext{
*Correspondence: salvator@unime.it

${ }^{\dagger}$ Equal contributors

'Department of Biological and Environmental Sciences, University of Messina, Viale Ferdinando Stagno D'Alcontres, 31-98166 Messina, Italy

${ }^{3}$ Manchester Biomedical Research Centre, Manchester Royal Infirmary, School of Medicine, University of Manchester, 29 Grafton Street Manchester, M13 9WU Manchester, UK

Full list of author information is available at the end of the article
} 


\section{Background}

Traumatic brain injury (TBI) is a growing public health concern worldwide. There are over 1.35 million emergency room visits and 275,000 hospitalizations for nonfatal TBI each year in the United States, and approximately $40 \%$ of these individuals suffer from long-term disability due to their injury [1]. The pathophysiology of TBI can be divided into primary and secondary brain injury [2]. Primary injury results from the direct, physical brain trauma with tissue distortion, shearing, vascular injury and cell destruction probably related to rotational acceleration and deceleration inertial forces. Secondary brain injury is related to destructive inflammation and biochemical changes. Secondary injury onsets within minutes of primary injury, may last for several days and contributes to final outcome [3]. Primary and secondary brain injuries induce cerebral edema and bleeding. During secondary neuronal injury, healthy neurons around the injury site progressively degenerate, eventually leading to more serious clinical symptoms. Therefore, secondary neuronal injury plays a key role in the severity of insult and subsequent clinical prognosis.

Non-steroidal anti-inflammatory drugs (NSAIDs) are among the most commonly used anti-inflammatory drugs, but their use is associated with significant, sometimes lifethreatening, adverse effects, particularly in the gastrointestinal (GI) tract [4]. Along with nitric oxide $(\bullet \mathrm{NO})$ and carbon monoxide $(\mathrm{CO})$, hydrogen sulfide $\left(\mathrm{H}_{2} \mathrm{~S}\right)$ is regarded as an important gasotransmitter and endogenous neuromodulator, drawing increasing attention in the literature. Traditional neurotransmitters bind and activate membrane receptors, while gasotransmitters can freely diffuse to adjacent cells and directly bind to their target proteins to modify biological functions. Therefore, $\mathrm{H}_{2} \mathrm{~S}$ is a physiologic gasotransmitter as important as $\bullet \mathrm{NO}$ and $\mathrm{CO}$. In the past decade, increasing evidence shows that $\mathrm{H}_{2} \mathrm{~S}$ plays multiple roles in the CNS under physiological and pathological states. $\mathrm{H}_{2} \mathrm{~S}$ is produced in various parts of the body including the heart [5], the cardiovascular system [6] and the central nervous system (CNS) [7]. With respect to the $\mathrm{CNS}, \mathrm{H}_{2} \mathrm{~S}$ has been reported to exert neuroprotective and neuromodulatory effects $[8,9]$. Thus, $\mathrm{H}_{2} \mathrm{~S}$ has recently been exploited in the design of novel NSAID derivatives that exhibit little, if any, side effects in the GI tract, despite producing suppression of prostaglandin synthesis and reduction of inflammation at least as effectively as the parent NSAID [10]. Recently, beneficial effects of an $\mathrm{H}_{2} \mathrm{~S}$ releasing derivative of naproxen have been shown in an animal model of spinal cord injury (SCI), significantly enhancing recovery of motor function, possibly by reducing the secondary inflammation and tissue injury that characterizes this model. The combination of inhibition of cyclooxygenase [11] and delivery of $\mathrm{H}_{2} \mathrm{~S}$ may offer a promising alternative to existing therapies for traumatic injury [12]. On the basis of these data, $\mathrm{H}_{2} \mathrm{~S}$ could have an important role in reducing inflammatory processes and tissue damage post-brain trauma. Therefore, in the current study we evaluated ATB-346, a novel $\mathrm{H}_{2} \mathrm{~S}$-releasing derivative of naproxen, for neuroprotective properties in experimental murine TBI using controlled cortical impact injury (CCI), a model of focal brain injury. Moreover, the aim of the present study was to carefully investigate molecular pathways and subtypes of glial cells involved in the protective effect of ATB-346 on inflammatory reaction associated with an experimental model of TBI. In particular, our attention shifts to post-injury recovery of motor function, reduction of infarct area and of brain tissue inflammation after TBI.

\section{Methods \\ Animals}

Male CD1 mice (25 to 30 g, Harlan, Milan, Italy), aged between 10 and 12 weeks, were used for all studies. Mice were housed in individual cages (five per cage) and maintained under a 12:12 hour light/dark cycle at $21 \pm 1^{\circ} \mathrm{C}$ and $50 \pm 5 \%$ humidity. Standard laboratory diet and tap water were available ad libitum. The study was approved by the University of Messina Review Board for the care of animals. Animal care was in compliance with Italian regulations on protection of animals used for experimental and other scientific purposes (Ministerial Decree 16192) as well as with the Council Regulation (EEC) (Official Journal of the European Union L 358/1 12/18/1986).

\section{Controlled cortical impact experimental traumatic brain injury}

TBI was induced in mice by a controlled cortical impactor. The mice were anesthetized under intraperitoneal ketamine and xylazine $(2.6 / 0.16 \mathrm{mg} / \mathrm{kg}$ of body weight, respectively). A craniotomy was made in the right hemisphere, encompassing bregma and lambda, and between the sagittal suture and the coronal ridge, with a Micro motor hand piece and drill (UGO Basile SRL, Comerio Varese, Italy). The resulting bone flap was removed and the craniotomy enlarged further with cranial rongeurs (New Adalat Garh, Roras Road, Pakistan). A cortical contusion was produced on the exposed cortex using the controlled impactor device Impact One ${ }^{\mathrm{TM}}$ Stereotaxic impactor for CCI (Leica, Milan, Italy). Briefly, the impacting shaft was extended, and the impact tip was centered and lowered over the craniotomy site until it touched the dura mater. Then, the rod was retracted and the impact tip was advanced farther to produce a brain injury of moderate severity for mice (tip diameter: $4 \mathrm{~mm}$; cortical contusion depth: $3 \mathrm{~mm}$; impact velocity: $1.5 \mathrm{~m} / \mathrm{sec}$ ). Immediately after injury, the skin incision was closed with nylon sutures, and $2 \%$ lidocaine jelly was applied to the lesion site to minimize any possible discomfort. 


\section{Test drugs}

ATB-346 (2-(6-methoxynapthalen-2-yl)-propionic acid 4thiocarbamoyl phenyl ester) is a derivative of naproxen, which includes a $\mathrm{H}_{2} \mathrm{~S}$-releasing moiety referred to hereafter as 'TBZ' (4-hydroxythiobenzamide) [13]. ATB-346, TBZ and naproxen were prepared freshly each day as suspensions in dimethylsulfoxide:1\% carboxymethylcellulose (5:95).

Prior to beginning these experiments, a pilot study was performed to confirm the equipotency of naproxen and ATB-346 in suppressing cyclooxygenase at the dose selected. At $30 \mu \mathrm{mol} / \mathrm{kg}$ (oral administration), naproxen and ATB-346 equally suppressed gastric (prostaglandin E2) $\mathrm{PGE}_{2}$ synthesis (by more than 90\%) and whole blood thromboxane synthesis ( by more than 95\%). This level of inhibition was evident within 15 minutes and persisted for at least 12 hours after drug administration. TBZ had no effect on gastric $\mathrm{PGE}_{2}$ synthesis or whole blood thromboxane synthesis.

\section{Experimental groups}

Mice were randomly allocated into one of five groups. In the TBI + vehicle group, mice were subjected to TBI and received the vehicle for TBZ, naproxen and ATB-34 (dimethylsulfoxide:1\% carboxymethylcellulose) (orally), at one and six hours after brain trauma $(\mathrm{N}=20)$. The TBZ group was the same as the TBI + vehicle group, but mice were administered TBZ only ( $30 \mu \mathrm{mol} / \mathrm{kg}$, orally), at one and six hours after brain trauma $(\mathrm{N}=20)$. The naproxen group was the same as the TBI + vehicle group, but mice were administered naproxen only $(30 \mu \mathrm{mol} / \mathrm{kg}$, orally), at one and six hours after brain trauma $(\mathrm{N}=20)$. The ATB346 group was the same as the TBI + vehicle group, but mice were administered ATB-346 only (30 $\mu \mathrm{mol} / \mathrm{kg}$, orally), at one and six hours after brain trauma $(\mathrm{N}=20)$. In the sham + vehicle group mice were subjected to identical surgical procedures, except for TBI, and were kept under anesthesia for the duration of the experiment $(\mathrm{N}=20)$.

As described below, mice were sacrificed at 24 hours after TBI in order to evaluate the following parameters: 2,3,5-triphenyltetrazolium chloride (TTC) staining $(\mathrm{N}=$ four out of 20 for each group) [14]; histology analysis ( $\mathrm{N}=$ three out of 20 for each group) and Tumor necrosis factor (TNF) $\alpha$, Interleukin (IL)-1 $\beta$, Glial fibrillary acidic protein (GFAP) and Ionized calcium binding adaptor molecule (Iba) 1 immunofluorescence $(\mathrm{N}=$ three out of 20 for each group) [14]; Western blot analysis ( $\mathrm{N}=$ five out of 20 for each group) and RT-PCR analysis for Glial cell-Derived Neurotrophic Factor (GDNF), Nerve Growth Factor (NGF) and Vascular Endothelial Growth Factor (VEGF) levels ( $\mathrm{N}$ = five out of 20 for each group). In a separate set of experiments, another 10 animals from each group were observed after TBI in order to evaluate the behavioral testing. Several recent results illustrate the importance of initiating therapeutic interventions as soon as possible following TBI, preferably within four hours post-injury, to achieve the best possible neuroprotective effect [15].

\section{Behavioural testing}

Mice with TBI display motor and cognitive deficits. Thus, the present behavioural tests involved analyses of motor asymmetry (elevated biased swing test (EBST) and rotarod test). Training for the rotarod test was initiated at one week. Before the CCI injury, whereas no training was required for the EBST. The retard treadmill (Accuscan, Inc., Columbus, Ohio, United States) provided a motor balance and coordination assessment. Data were generated by averaging the scores (total time spent on treadmill divided by five trials) for each animal during training and testing days. Each animal was placed in a neutral position on a cylinder $(3 \mathrm{~cm}$ and $1 \mathrm{~cm}$ diameter for rats and mice, respectively) then the rod was rotated with the speed accelerated linearly from 0 to 24 rpm within 60 seconds, and the time spent on the retard was recorded automatically. The maximum score given to an animal was fixed to 60. For training, animals were given five trials each day and declared having reached the criterion when they scored 60 in three consecutive trials. For testing, animals were given three trials and the average score of these three trials was used as the individual rotarod score. The EBST provided a motor asymmetry parameter and involved handling the animal by its tail and recording the direction of the biased body swings. The EBST consisted of 20 trials with the number of swings ipsilateral and contralateral to the injured hemisphere recorded and expressed in percentage to determine the biased swing activity.

\section{Quantification of infarct volume}

Mice were anesthetized with ketamine and decapitated. Their brains were carefully removed. The brains were cut into five coronal slices of 2-mm thickness. Slices were incubated in a $2 \%$ solution of TTC at $37^{\circ} \mathrm{C}$ for 30 minutes and immersion fixed in $10 \%$ buffered formalin solution. TTC stains the viable brain tissue red while infracted tissue remains unstained [16,17]. For quantification of infracted area and volumes, the brain slices were photographed using a digital camera (HP Photosmart R707, Milan, Italy) and then image analysis was performed on a personal computer with an image analysis software program (using ImageJ for Windows (Institute of Mental Health, Maryland, USA). To compensate for the effect of brain edema the corrected infarct volume was calculated as previously described in detail [18]:

\section{Corrected infarct area $=$ left hemisphere area - (right} hemisphere area - infarct area). 
Values are given as mean \pm SEM. The corrected total infarct volume was calculated by summing the infarct area in each slice and multiplying it by slice thickness $(2 \mathrm{~mm})$.

\section{Tissue processing and histology}

Coronal sections of 5- $\mu \mathrm{m}$ thickness were sectioned from the perilesional brain area of each animal and were evaluated by an experienced histopathologist. Damaged neurons were counted and the histopathologic changes of the grey matter were scored on a six-point scale [19]: 0, no lesion observed; 1 , grey matter contained one to five eosinophilic neurons; 2, grey matter contained five to 10 eosinophilic neurons; 3 , grey matter contained more than 10 eosinophilic neurons; 4, small infarction (less than one third of the grey matter area); 5 , moderate infarction (one third to one half of the grey matter area); 6, large infarction (more than half of the grey matter area). The scores from all the sections of each brain were averaged to give a final score for individual mice. All the histological studies were performed in a blinded fashion.

\section{Western blot analyses}

Cytosolic and nuclear extracts were prepared as previously described [20], with slight modifications. The ipsilateral hemisphere after injury from each mouse was suspended in extraction Buffer A containing protease inhibitors, homogenized for two minutes, then centrifuged at $1,000 \times \mathrm{g}$ for 10 minutes at $4^{\circ} \mathrm{C}$. Supernatants contained the cytosolic fraction. The pellets, containing enriched nuclei, were resuspended in Buffer B containing 1\% Triton X-100, $150 \mathrm{mM} \mathrm{NaCl}, 10 \mathrm{mM}$ Tris- $\mathrm{HCl}$ pH 7.4, $1 \mathrm{mM}$, ethylene glycol tetraacetic acid (EGTA), 1 $\mathrm{mM}$, ethylenediaminetetraacetic acid (EDTA), $0.2 \mathrm{mM}$ phenylmethanesulfonylfluoride (PMSF) and protease inhibitors. After centrifugation for 30 minutes at 15,000 $\times$ $g$ at $4^{\circ} \mathrm{C}$, the supernatants containing the nuclear protein were stored at $-80^{\circ} \mathrm{C}$ for further analysis. The levels of inducible nitric oxide synthase (iNOS), cyclooxygenase (COX)-2, endothelial nitric oxide synthase (eNOS) and I $\mathrm{B} \alpha$ were quantified in cytosolic fractions. NFkBp65 was quantified in nuclear fractions from brain tissue collected 24 hours after TBI. The filters were probed with specific Abs anti-iNOS (1:1,000; BD Biosciences, Milan, Italy), anti-COX-2 (1:1,000; Cayman Chemicals, Tallinn Estonia), anti-eNOS (1:1000; BD Biosciences, Milan, Italy), anti-NFkBp65 (1:500; Santa Cruz Biotechnology, Heidelberg, Germany) and anti-IкB $\alpha$ antibody (1:500; Santa Cruz Biotechnology, Heidelberg, Germany) at $4{ }^{\circ} \mathrm{C}$ overnight in $1 \times \mathrm{PBS}, 5 \%(\mathrm{w} / \mathrm{v})$, non-fat dried milk and $0.1 \%$ Tween-20 (PMT). Membranes were incubated with peroxidase-conjugated bovine anti-mouse IgG secondary antibody or peroxidase-conjugated goat anti-rabbit IgG (1:2,000; Jackson ImmunoResearch, West Grove, PA, USA) for one hour at room temperature. To ascertain that blots were loaded with equal amounts of protein lysates, they were also incubated in the presence of the antibody against $\beta$-actin or lamin A/C (1:5,000; Santa Cruz Biotechnology, Heidelberg, Germany). The signals were detected with enhanced a chemiluminescence detection system reagent according to manufacturer's instruction (Super Signal West Pico Chemiluminescent Substrate, Pierce Thermo Scientific, Rockford, IL. USA). The relative expression of the protein bands of IKB $\alpha$ (approximately 37 $\mathrm{kDa}$ ), NFkB (approximately $65 \mathrm{kDa}$ ), eNOS (approximately $140 \mathrm{kDa}$ ), iNOS (approximately $130 \mathrm{kDa}$ ) and COX-2 (approximately $72 \mathrm{kDa}$ ) were quantified by densitometry with Gel Logic 200 PRO software (GE Healthcare, Milwaukee, Wisconsin, USA) and standardized to $\beta$-actin and lamin $\mathrm{A} / \mathrm{C}$ levels. Images of blot signals were imported to analysis software Image Quant TL Software, version 2003 (GE Healthcare, Milwaukee, Wisconsin, USA). A preparation of commercially available molecular weight 10 to $250 \mathrm{kDa}$ was used to define molecular weight positions, and as reference concentrations for each molecular weight.

\section{Reverse transcription polymerase chain reaction}

Total RNA, from contused brain tissue at the impact site after injury, was extracted by a modified method [21], using TRIzol ${ }^{\text {tw }}$ Reagent (Life Technologies, Milan, Italy) according to the manufacturer's instructions. Reverse transcription was performed by a standard procedure using 2 $\mu \mathrm{g}$ of total RNA. After reverse transcription, $1 \mu \mathrm{l}$ of reverse transcriptase (RT) products were diluted in $24 \mu \mathrm{l}$ of PCR mix, to give a final concentration of $50 \mathrm{U} \mathrm{ml}-1$ of Taq DNA polymerase (Life Technologies, Milan, Italy), $10 \mu \mathrm{m}$ of $5^{\prime}$ and $3^{\prime}$ primers, $10 \mathrm{mM}$ of each deoxynucleotide triphosphates (dNTP), $50 \mathrm{mM} \mathrm{MgCl} 2$ and $10 \times \mathrm{NH} 4$ buffer. cDNAs underwent 30 cycles for GDNF, NGF, VEGF and $\beta$-actin, each one performed at $94^{\circ} \mathrm{C}$ for one minute, melting temperature $(\mathrm{Tm}){ }^{\circ} \mathrm{C}$ for 45 seconds and $72^{\circ} \mathrm{C}$ for 55 seconds (Table 1). After this treatment $10 \mu \mathrm{l}$ of RT-PCR products were separated by $1.5 \%$ agarose gel electrophoresis in Tris/Borate/EDTA (TBE) $0.5 \times$ (Tris-base $0.089 \mathrm{~m}$, boric acid $0.089 \mathrm{~m}$ ) containing $0.1 \mu \mathrm{g} \mathrm{ml}^{-1}$ of ethidium bromide. Fragments of DNA were seen under ultraviolet light. $\beta$-actin was used as an internal reference.

\section{Immunofluorescence}

After deparaffinization and rehydration, detection of TNF $\alpha$, IL-1 $\beta$, GFAP and Iba1 was carried out after boiling in 0.1 $M$ citrate buffer for one minute. Non-specific adsorption was minimized by incubating the section in $2 \%$ (volume/ volume (vol/vol)) normal goat serum in PBS for $20 \mathrm{mi}-$ nutes. Sections were incubated with mouse monoclonal anti-GFAP (1:100, vol/vol Santa Cruz Biotechnology (Heidelberg, Germany), or with polyclonal rabbit antiTNF $\alpha$ (1:100, vol/vol Santa Cruz Biotechnology, Heidelberg, Germany), or with rabbit anti-IL-1 $\beta$ (1:100, vol/vol Santa 
Table 1 Specific primer sequences

\begin{tabular}{lll}
\hline Gene & Forward primer $\left(\mathbf{5}^{\prime}-\mathbf{-}>\mathbf{3}\right.$ ') & Reverse primer $\left(\mathbf{5}^{\prime}\right.$-- $>\mathbf{3}$ ) \\
\hline GDNF & TCA CTG ACT TGG GTT TGG & TCA GAC GGC TGT TCT CAC \\
& GCT AT & TCC TA \\
NGF & GCA TCG AGT GAC TाT GGA & GTA CGC CGA TCA AAA ACG \\
& GC & CA \\
VEGF & TGG ATG TCT ACC AGC GAA & ACA AGG CTC ACA GTG ATT \\
& GC & TT \\
$\beta$ - actin & CAT GAA GTG CGA CGT TGA & CAC ATC TGC TGG AAG GTG \\
& CA & GA \\
\hline
\end{tabular}

Cruz Biotechnology, Heidelberg, Germany) or with mouse monoclonal anti-Iba1 (1:100, vol/vol Santa Cruz Biotechnology, Heidelberg, Germany) antibody in a humidified oxygen and nitrogen chamber for over night at $37^{\circ} \mathrm{C}$. Sections were incubated with secondary antibody Fluorescein isothiocyanate (FITC)-conjugated anti-mouse Alexa Fluor-488 antibody (1:2,000 vol/vol Molecular Probes, Monza, Italy) and with TEXAS RED-conjugated anti-rabbit Alexa Fluor-594 antibody (1:1000 in PBS, vol/ vol Molecular Probes, Monza, Italy) for one hour at $37^{\circ} \mathrm{C}$. For nuclear staining, $2 \mu \mathrm{g} / \mathrm{ml} \mathrm{4'}$ ',6'-diamidino-2-phenylindole (DAPI; Hoechst, Frankfurt, Germany) in PBS was added. Sections were observed at $20 \times$ magnification using a Leica DM2000 microscope (Leica, Milan, Italy). Optical sections of fluorescence specimens were obtained using a HeNe laser (543 nm), an ultraviolet laser (361 to $365 \mathrm{~nm}$ ) and an argon laser $(458 \mathrm{~nm})$ at a one-minute, two seconds scanning speed with up to eight averages; $1.5 \mu \mathrm{m}$ sections were obtained using a pinhole of 250 . Contrast and brightness were established by examining the most brightly labeled pixels and applying settings that allowed clear visualization of structural details, while keeping the highest pixel intensities close to 200. The same settings were used for all images obtained from the other samples that had been processed in parallel. Digital images were cropped and figure montages prepared using Adobe Photoshop 7.0 (Adobe Systems; Palo Alto, California, United States).

\section{Materials}

ATB-346 (2-(6-methoxy-napthalen-2-yl)-propionic acid 4thiocarbamoyl-phenyl ester), sodium naproxen and TBZ (4-hydroxythiobenzamide) were provided by Antibe Therapeutics Inc. (Toronto, Canada). Unless otherwise stated, all other compounds were obtained from Sigma-Aldrich Company Ltd. (Milan, Italy). All stock solutions were prepared in non-pyrogenic saline $(0.9 \% \mathrm{NaCl}$; Baxter, Italy) or $10 \%$ dimethyl sulfoxide (DMSO).

\section{Statistical evaluation}

Data are mean \pm SEM. Data were analyzed using Graphpad PRISM V (Graphpad Software Inc., La Jolla, California, United States). Swing activity and time on platform were analyzed using two factor repeated measures analysis of variance (RM ANOVA, group $\times$ time). Infarct area, lesion volume and densitometric analysis data were analyzed by ANOVA followed by a Bonferroni post-hoc test for multiple comparisons. Histological score and percentage total tissue area were analyzed by Student's t-test. For all comparisons, $P<0.05$ was considered to be significant. In the experiments involving histology or immunohistochemistry, the figures shown are representative of at least three experiments performed on different experimental days on the tissue sections collected from all the animals in each group.

\section{Results}

\section{Effect of ATB-346 on IKBa degradation and NFKBp65 translocation}

To investigate whether the cellular mechanism through ATB-346 could attenuate inflammatory processes we assessed Western blot analysis of the ipsilateral hemisphere after TBI, using an IкB $\alpha$ and an NFkB-specific antibodies. The results showed a basal expression of ІкB $\alpha$ in the brain from sham-mice (Figure 1A, see densitometry analysis $\mathrm{A} 1$ ), while ІкB $\alpha$ expression was significantly reduced in mice subject to TBI and TBZ administration, as showed in Figure 1A and 1A1. Naproxen treatment blunted the degradation of IкB $\alpha$ but ATB-346 was able to significantly restore IкB $\alpha$ degradation (Figure $1 \mathrm{~A}$, see densitometry analysis A1). Moreover, p65 subunit translocation was increased after TBI and TBZ injection in the nuclear brain homogenates, compared with sham-group. ATB-346 administration significantly reduced the translocation of p65 in nuclei compared to the TBI group (Figure 1B, see densitometry analysis B1).

\section{Effect of ATB-346 on iNOS and COX-2 expression}

To determine the role of $\bullet \mathrm{NO}$ produced during TBI, iNOS expression was evaluated by Western blot analysis. A significant increase in iNOS expression was observed in the contused area from mice subjected to TBI and TBZ administration (Figure $1 \mathrm{C}$, see densitometry analysis $\mathrm{C} 1$ ). Consequently, naproxen reduced TBI-induced iNOS expression (Figure $1 \mathrm{C}$, see densitometry analysis $\mathrm{C} 1$ ); on the other hand, a significant decrease in iNOS expression was observed after ATB-346 treatment (Figure 1C see densitometry analysis $\mathrm{C} 1$ ). Similarly, COX-2 expression was induced by TBI and TBZ administration compared to the sham group (Figure 1D, see densitometry analysis D1). Both treatments with naproxen and ATB-346 lowered COX-2 expression (Figure 1D, see densitometry analysis D1).

Effect of ATB-346 on TNFa and IL-1 $\beta$ expression in astrocytes after traumatic brain injury

To analyse the activation of astrocytes and cytokines expression, contused brain tissue at the impact site after injury was double-stained with antibodies against GFAP 


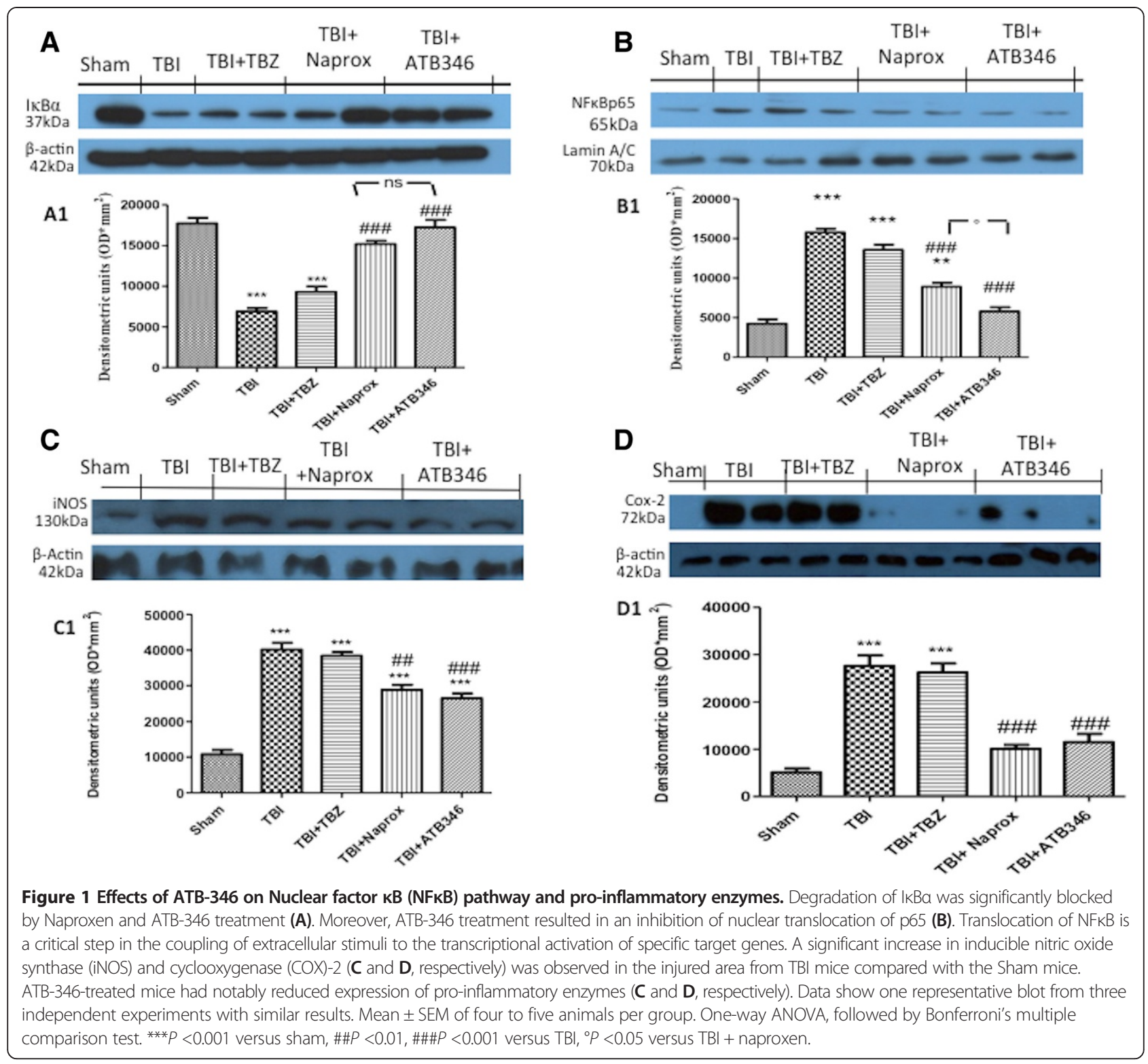

(green; Figures 2 and 3) and TNFa (red; Figure 2) or IL$1 \beta$ (red; Figure 3). Brain sections revealed increased astrogliosis (GFAP+ cells) in TBI and TBZ panels. Moreover, a marked co-localization of TNF $\alpha$ in GFAP+ cells was present after TBI and TBZ administration (merged, Figure 2). TNF $\alpha$ and IL-1 $\beta$ expressions were significantly reduced by ATB-346 treatment (TBI + ATB-346 panels; Figures 2 and 3).

\section{Effect of ATB-346 on TNFa and IL-1 $\beta$ expression in microglia after traumatic brain injury}

To evaluate the microglia activation and its correlation with cytokines expression, ipsilateral hemisphere to the injury site were double-stained with antibodies against Iba1 (green; Figures 4 and 5) and TNF $\alpha$ (red; Figure 4) or IL-1 $\beta$ (red; Figure 5). Microglial cells (Iba1-+ cells) expressed TNF $\alpha$ and IL-1 $\beta$ in TBI and TBZ panels (Figures 4 and 5, respectively). There was an evident colocalization of TNF $\alpha$ and Ibal in TBI and TBZ panels (merged, Figure 4). Considerable reductions in cytokines expressions were evident in naproxen panels (Figures 4 and 5, respectively); however, ATB-346 reduced TNFo and IL$1 \beta$ expressions in microglia (Figures 4 and 5 , respectively).

Effect of ATB-346 on mRNA levels of neurotrophic factors To test whether ATB-346 modulates the levels of the neurotrophic factors, we studied GDNF and NGF levels in brain tissue using semi-quantitative RT-PCR analysis. A significant decrease in GDNF (470 bp) and NGF (318 bp) mRNA expression following TBI and TBZ administration 


\begin{tabular}{|c|c|c|c|c|}
\hline & GFAP & TNF $\alpha$ & DAPI & MERGED \\
\hline Sham & & & & \\
\hline TBI & & & 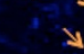 & \\
\hline$T B I+T B Z$ & $\begin{array}{ll}4 \\
y\end{array}$ & $\begin{array}{ll}4 \\
y\end{array}$ & $\begin{array}{ll}4 \\
1\end{array}$ & y. \\
\hline $\begin{array}{c}\text { TBI + } \\
\text { Naproxen }\end{array}$ & $y y$ & ע & 21 & 4 \\
\hline $\begin{array}{c}\text { TBI + } \\
\text { ATB-346 }\end{array}$ & & & & \\
\hline $\begin{array}{l}\text { Figure } 2 \text { Effects of ATB-346 on } \\
\text { was double-stained with antibodie } \\
\text { revealed increased astrogliosis (GF } \\
\text { expression was significantly reduce } \\
\text { All images were digitalized at } 600\end{array}$ & $\begin{array}{l}\text { or necro } \\
\text { gainst GF, } \\
\text { cells) in } \\
\text { y ATB-34 }\end{array}$ & $\begin{array}{l}\text { JF)a expre } \\
\text { TNFa (re } \\
\text { anels. Con } \\
\text { BI + ATB-3 }\end{array}$ & $\begin{array}{l}\text { fibrillar } \\
\text { s indica } \\
\text { immun } \\
\text { pared t }\end{array}$ & $\begin{array}{l}\text { (GFAP) posit } \\
\text { zations (merge } \\
\text { present in TBI } \\
\text { tment (TBI + n }\end{array}$ \\
\hline
\end{tabular}

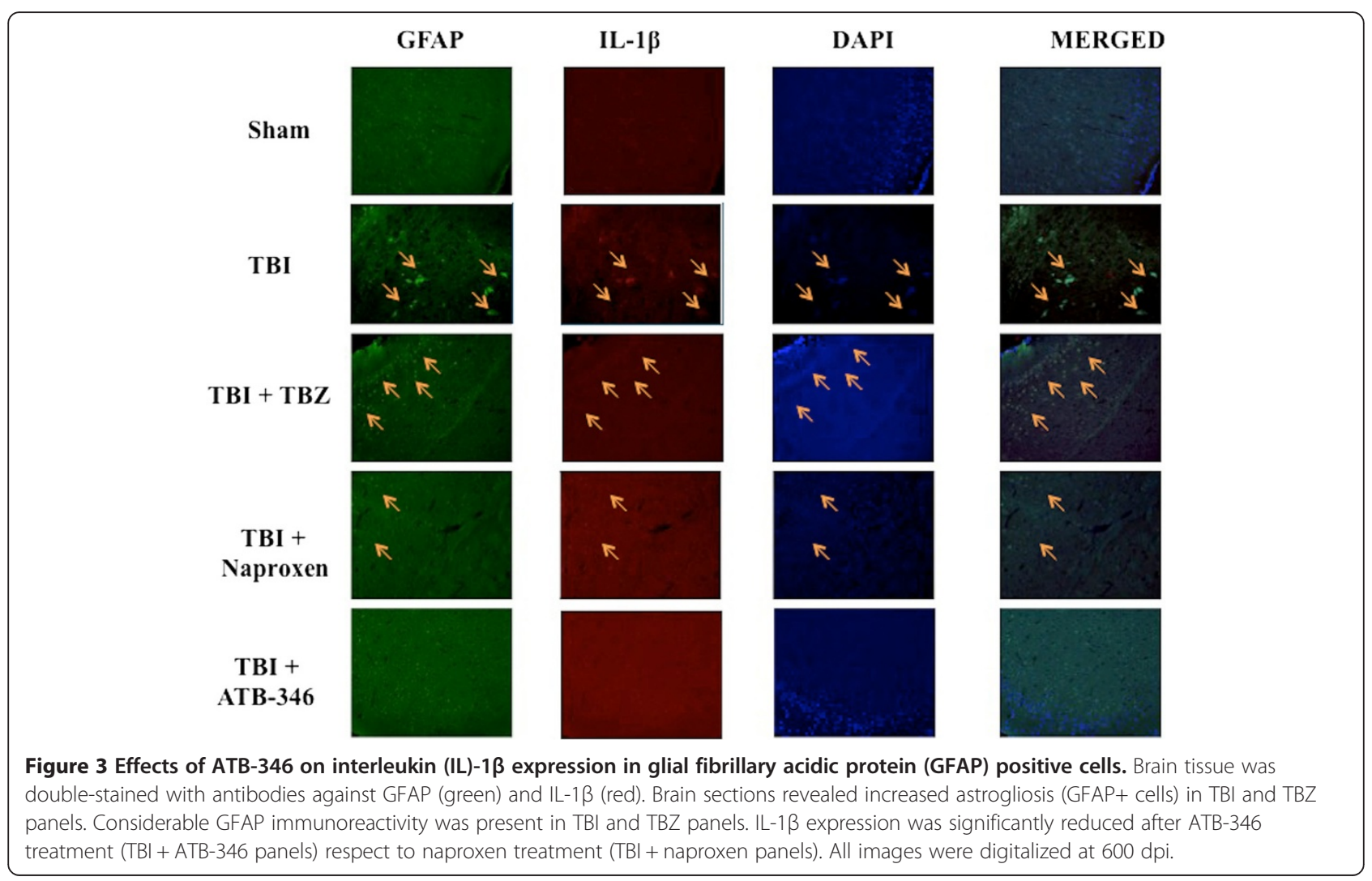




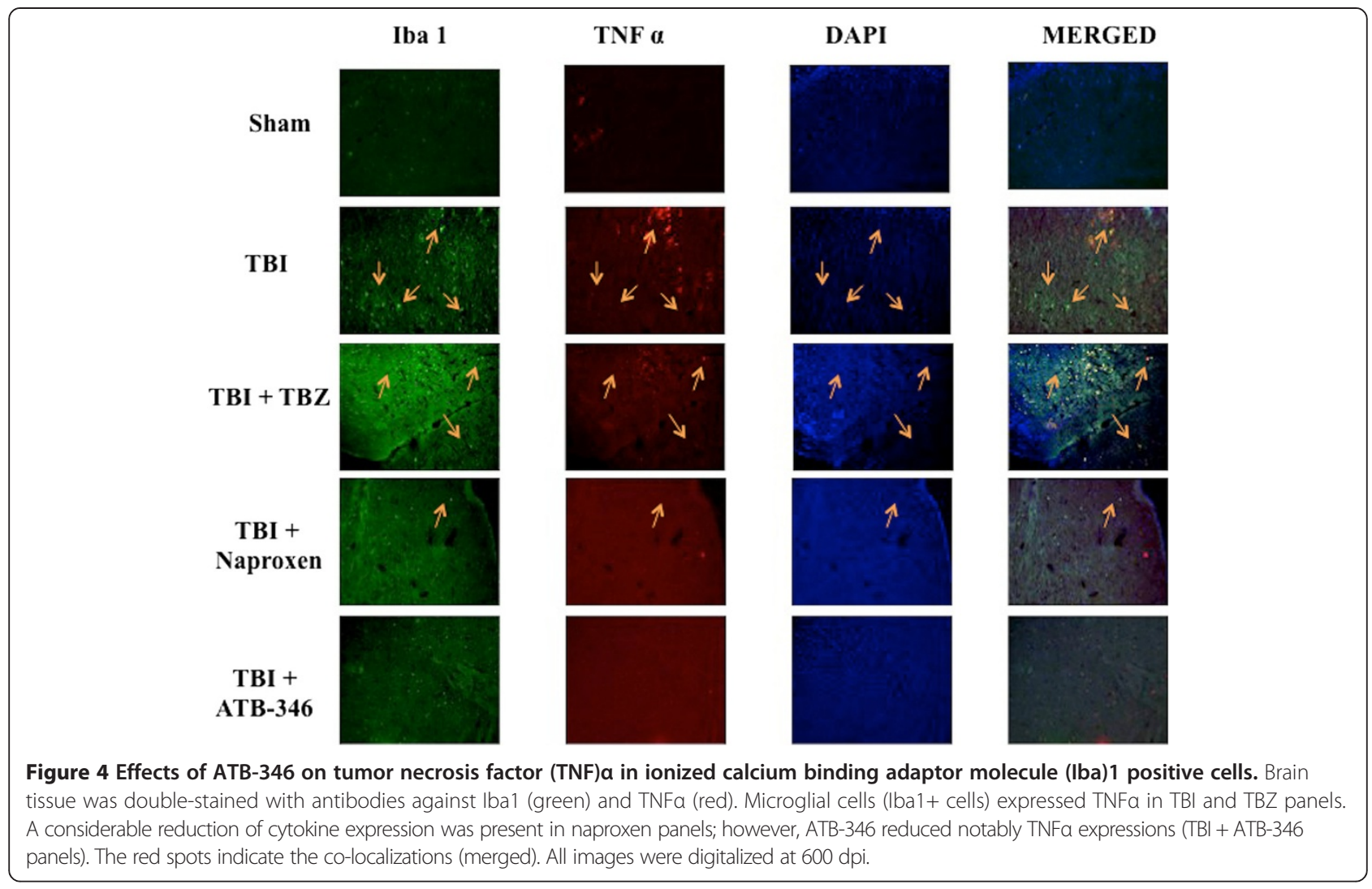

was evident. Moreover, ATB-346 significantly increased mRNA levels of both neurotrophic factors examined (Figure 6A and $\mathrm{B}$ respectively, see densitometry analysis $\mathrm{A} 1$ and $\mathrm{B} 1$ respectively).

Effect of ATB-346 on vascular components after traumatic brain injury

To investigate whether ATB-346 could promote normalization of the impaired neurovascular unit, we observed VEGF level and eNOS expression. RT-PCR showed a significant increase in VEGF (308 bp) mRNA expression, and ATB-346 significantly increased its level (Figure 6C, see densitometry analysis $\mathrm{C} 1$ ). Moreover, by Western blot analysis we observed a significantly increase in eNOS expression in the TBI group, and ATB-346 upregulated its expression (Figure 6D, see densitometry analysis D1).

\section{Infarct outcome in ATB-346-treated mice after traumatic brain injury}

A histological examination of brain sections at the level of the perilesional area, stained 24 hours after injury, revealed significant damage in the TBI and TBI + TBZ groups, such as prominent and thickened blood vessels, ischemic changes and gliosis in the brain parenchyma (Figure 7B and $\mathrm{C}$ respectively, see densitometry analysis $\mathrm{F}$ ) compared to sham mice (Figure 7A, see densitometry analysis F).
Naproxen treatment attenuated the development of inflammation at 24 hours after TBI; ATB-346 significantly reduced the degree of brain injury (Figure $7 \mathrm{D}$ and $\mathrm{E}$ respectively, see densitometry analysis F).

Brain edema indicates pathology associated with endothelial cell activation and endothelial dysfunction. To evaluate the effect of ATB-346 on brain edema and infarctions in the TBI and TBZ group, we performed TTC staining (Figure 8A). At 24 hours after TBI, ATB-346-treated mice had a significantly smaller infarct area (Figure $8 \mathrm{~B}$ ) and volume (Figure 8C).

\section{Neurological deficits after ATB-346 administration}

To investigate the relationship between neurological deficits in the setting of TBI we used two different tests: the EBST and the rotarod test, considered the most sensitive vestibular motor test to assess motor function. The EBST provided a motor asymmetry parameter and involved handling the animal by its tail and recording the direction of the biased body swings. The EBST consisted of 20 trials with the number of swings ipsilateral and contralateral to the ischemic hemisphere recorded and expressed in percentage to determine the biased swing activity. Mice were tested seven days after TBI for both behavioral tests. CCIinjured mice and TBZ-treated mice displayed a range of impairments in locomotor tasks as showed in Figure 8D and $E$, respectively. Both groups of animals that received 


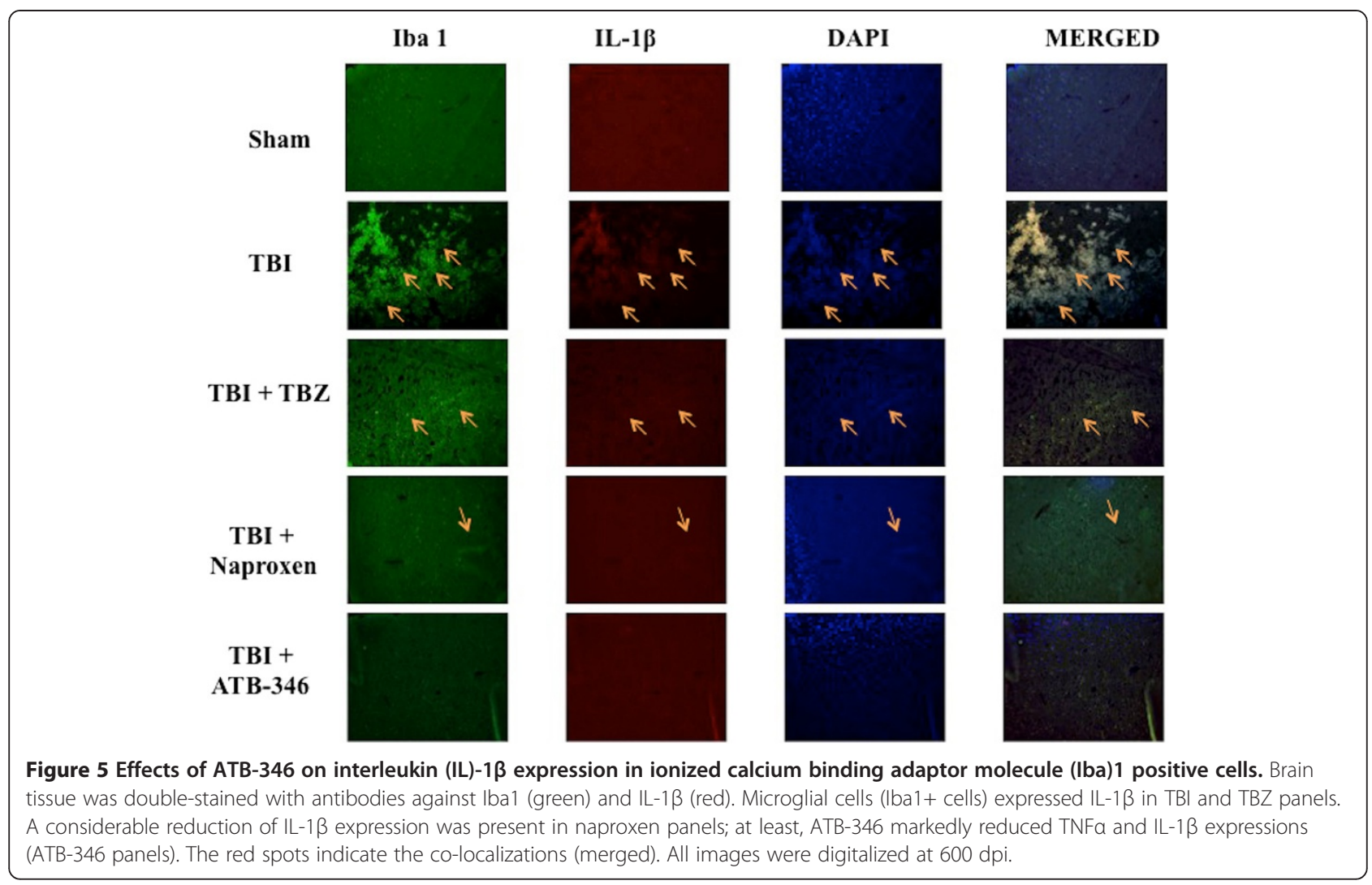

naproxen or ATB-346 were significantly less impaired in the EBST and rotarod tests compared with the TBI group (Figure 8D and E, respectively).

\section{Discussion}

A number of animal models have been developed to induce brain trauma. Of these the most commonly used are weight-drop injury, fluid percussion injury (FPI) and CCI. The use of TBI models has resulted in an increased understanding of the pathophysiology of TBI, including changes in molecular and cellular pathways and neurobehavioral outcomes. CCI models utilize a pneumatic pistol to laterally deform the exposed dura and provide controlled impact and quantifiable biomechanical parameters. This model produces graded, reproducible brain injury. Dependent on the severity of injury, CCI results in an ipsilateral injury with cortical contusion, hemorrhage and blood-brain barrier disruption. CCI injury reproduces changes reported in clinical head injuries such as cortical contusion, brain edema, subarachnoid hemorrhage, elevated intracerebral pressure, reduced cortical perfusion, decreased cerebral blood flow and neuro-endocrine and metabolic changes [22]. The predominantly focal brain injury caused by CCI makes this model to a useful tool for studying the pathophysiology of the secondary processes induced by focal brain injury. However, there is a lack of brain stem deformation in this model and thus a low mortality rate.
In recent years, $\mathrm{H}_{2} \mathrm{~S}$ has been recognized as a fundamental signalling molecule that plays important roles in exerting cytoprotective effects in the CNS, since it can protect neurons and glia from oxidative stress $[9,23]$. $\mathrm{H}_{2} \mathrm{~S}$ also exert many anti-inflammatory effects, including inhibition of leukocyte-endothelial adherence, reduction of edema formation [24,25] and inhibition of NFKB activation [26]. $\mathrm{H}_{2} \mathrm{~S}$ is produced endogenously via enzymatic activity, non-enzymatic pathways (such as reduction of thiol-containing molecules), and is also released from intracellular sulfur stores (sulfane sulfur). Cystathionine $\beta$-synthase (CBS) is believed to be the critical enzyme that produces $\mathrm{H}_{2} \mathrm{~S}$, resulting in the modulation of neurological function. $\mathrm{H}_{2} \mathrm{~S}$ generated by cystathionine $\gamma$-lyase (CSE) was next discovered as an important modulator of vasorelaxation in smooth muscle. They separately coordinate with L-cysteine to produce $\mathrm{H}_{2} \mathrm{~S}$, L-serine and ammonium. After the discovery of $\mathrm{H}_{2} \mathrm{~S}$ as a potential neurological and vasorelaxant signaling molecule, more targets were expected to be found $[27,28]$. The enhanced beneficial effects of ATB-346 over those of naproxen are most likely attributable to the $\mathrm{H}_{2} \mathrm{~S}$ release from the former, and may be due to the neuroprotective and antiinflammatory properties of this gaseous mediator, acting in a complimentary manner to the anti-inflammatory effects associated with inhibition of COX activity. Indeed, the marked reduction of gastrointestinal toxicity of 


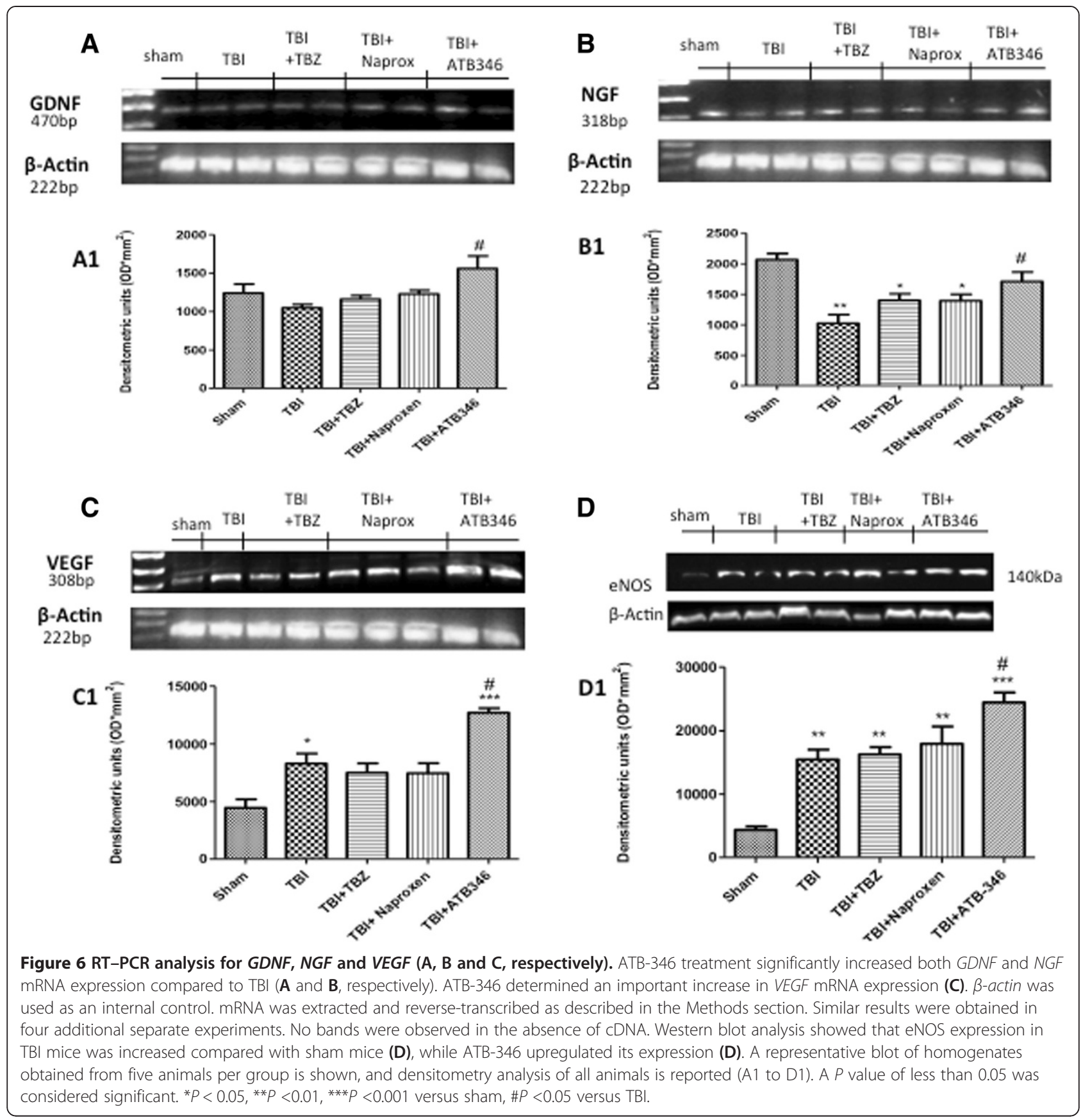

ATB-346 versus naproxen has been attributed to the mucosal protective and anti-inflammatory effects (for example, inhibition of leukocyte adherence to vascular endothelium) of the $\mathrm{H}_{2} \mathrm{~S}$ released from this drug [29]. We observe a light beneficial effect of TBZ, the H2Sreleasing moiety of ATB-346, on several parameters. The release of $\mathrm{H}_{2} \mathrm{~S}$ from TBZ may not be as great as that from an equimolar amount of ATB-346. Previous studies have shown that TBZ alone releases very little $\mathrm{H}_{2} \mathrm{~S}$, but when covalently linked to another drug, such as an NSAID, considerably more $\mathrm{H} 2 \mathrm{~S}$ is released [30].
Focal lesions to the brain display a characteristic inflammatory response with infiltration of peripheral immune cells after injury. These cells are believed to be important because they contain and release a multitude of inflammatory mediators associated with increased tissue injury. Neutrophils peak approximately two days post-TBI, and monocytes slightly later [31]. Leukocyte homogenates from post-TBI patients display upregulation of iNOS, COX-2 and nicotinamide adenine dinucleotide phosphate-oxidase; all enzymes involved in producing the damaging neutrophilic oxidative burst 

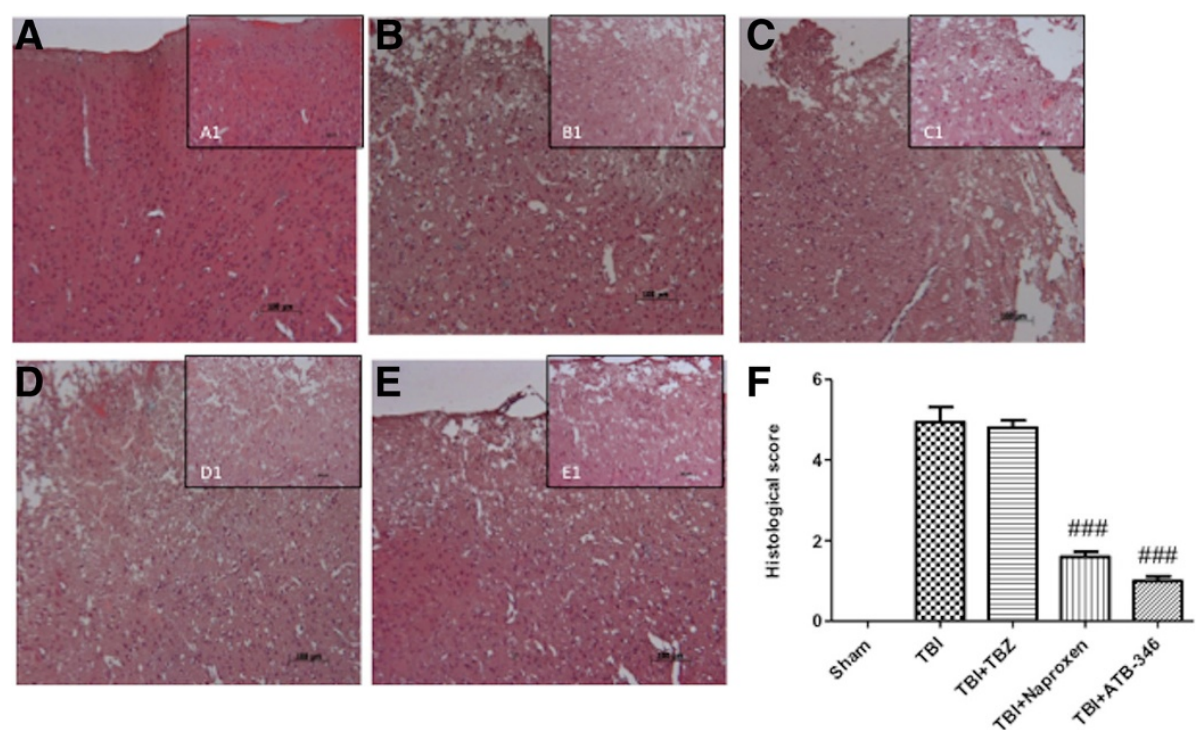

Figure 7 Histological examination of brain sections after $\mathbf{2 4}$ hours. Brain sections from TBI mice and TBZ-treated mice (B and $\mathbf{C}$ respectively, see densitometry analysis F) demonstrated brain tissue injury and inflammatory cell infiltration. Naproxen treatment did not attenuate completely the development of acute brain injury at one and six hours after TBI (D, see densitometry analysis F). On the contrary, ATB-346 treatment reduced the degree of brain injury and the inflammatory cells infiltration ( $\mathbf{E}$, see densitometry analysis $\mathbf{F}$ ). Figure is representative of at least three experiments performed on different experimental days. \#\#P <0.001 versus TBI.

[32]. To confirm the pathological contributions to brain inflammation, we have demonstrated here expression of COX-2 and iNOS in the injured tissue after TBI, but TBI-induced iNOS and COX-2 expression are significantly lower in injured brains from ATB-346-treated mice.

Post-TBI there is increased infiltration of neutrophils, astrocytosis, edema and both pro- and anti-inflammatory cytokines release. The major pro-inflammatory cytokines released are IL-1 $\beta$, IL- 6 and TNF $\alpha$. The anti-inflammatory cytokines are IL-10 and transforming growth factor beta. We demonstrate that increased microglial and astrocyte activation is present 24 hours after TBI. Moreover, immunofluorescence staining showed increased TNFa and IL-1 $\beta$ expression in astrocytes and microglia in TBI group. ATB-346 treatment importantly reduced TNF $\alpha$ and IL-1 $\beta$ expression in these glial cells. Apparently, ATB-346 might enhance actual functional neuronal regeneration via inhibiting glial scar formation during TBI.

Neurotrophic factors have well-established roles in survival, differentiation and function of CNS neurons. Exogenous $N G F$, for example, plays a critical role in neuronal plasticity and regenerative potential, as well as the inhibition of neural apoptosis after TBI [33,34]. A study found brain-derived neurotrophic factor,(BDNF) and neurotrophin-3 (NT-3) support the survival of injured CNS neurons in vitro and in vivo, induce neurite outgrowth and increase the expression of key enzymes for neurotransmitter synthesis [35]. GDNF is capable of protecting against hippocampal neuronal death [36], attenuating brain swelling and reducing the lesion volume [37] after TBI. Our results visibly showed restored GDNF and NGF levels after ATB-346 treatment, maintaining their protective action.

$V E G F$, an angiogenic growth and survival factor for endothelial cells that also exhibits neurotrophic and neuroprotective effects, has been implicated in neovascularization that precedes brain tissue repair and nerve regeneration following brain injury and is required to re-establish metabolic support [38]. VEGF is upregulated during many pathological events, and it is induced in astrocytes located in and surrounding edematous tissue following brain contusion [39]. Our study showed that ATB-346 significantly increased VEGF levels. Thus, it could be hypothesized that ATB-346-facilitated the increase in VEGF expression in the lesion area, resulting in the secretion of $V E G F$ from synthesizing cells and the restoration of the neurovascular unit.

-NO is a key regulator of cerebral circulation by its contribution to basal vascular tone that in vasculature is mainly derived from eNOS. eNOS is predominantly expressed by vessels endothelial cells and are also located in Purkinje cell bodies in the cerebellar cortex, olfactory bulb, dentate nucleus in granular layer and hippocampal pyramidal cells and astrocytes surrounding the cerebral blood vessels [40]. A recent paper showed that eNOS is central after trauma for the maintenance of blood flow in the injured cortex for at least 24 hours after TBI; this is based on the observation that eNOS knockout mice have lower cerebral blood flow at that 


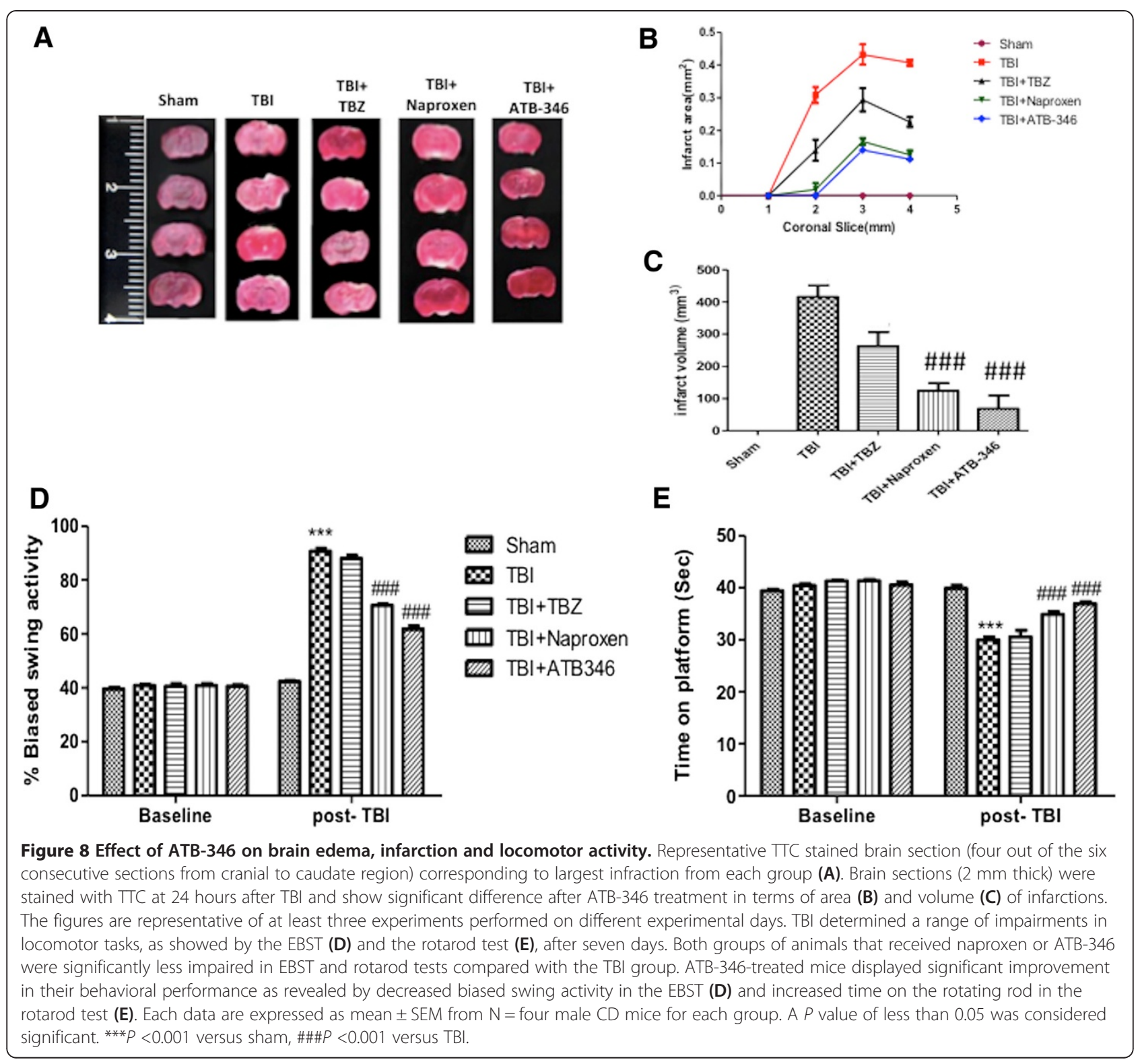

time point compared to wild-type mice [41]. According to this data, our results showed an evident increase in eNOS expression 24 hours after TBI. The increase in eNOS protein may represent either a protective or a reparative response, since it has been reported that eNOS is necessary to counteract posttraumatic cerebral hypoperfusion at 24 hours after CCI-TBI in mice [42]. There is substantial evidence that $\mathrm{H}_{2} \mathrm{~S}$ upregulates $\cdot \mathrm{NO}$ production in endothelial cells through the activation of eNOS, inducing angiogenesis and improving functional outcome [43-45]. Therefore, ATB 346 upregulates its expression, increasing functional protein expression and augmentation of cerebral blood flow, also in the brain. Furthermore, treatment with ATB-346 results in a significant reduction in inflammation and it is also accompanied by a detectable histological improvement of TBI. As shown in our recent paper, ATB-346 can markedly accelerate recovery of motor function in mice subjected to SCI [12]. Here, in a different model of neurotrauma, we confirmed that ATB346 significantly improved the latency compared to the naproxen group, indicated as a mediator of the mechanism to promote recovery and to enhance the repair mechanism. In the present study, post-TBI administration of ATB-346 not only facilitated functional recovery, but also reduced tissue damage within hours following injection. The ameliorating effect of ATB-346 at tissue level was further corroborated by its ability to reduce the extent of neurodegeneration. The neuroprotective basis for these actions seems to be dependent on the $\mathrm{H}_{2} \mathrm{~S}$-releasing moiety of ATB-346, as also stated in a recent paper [46]. 


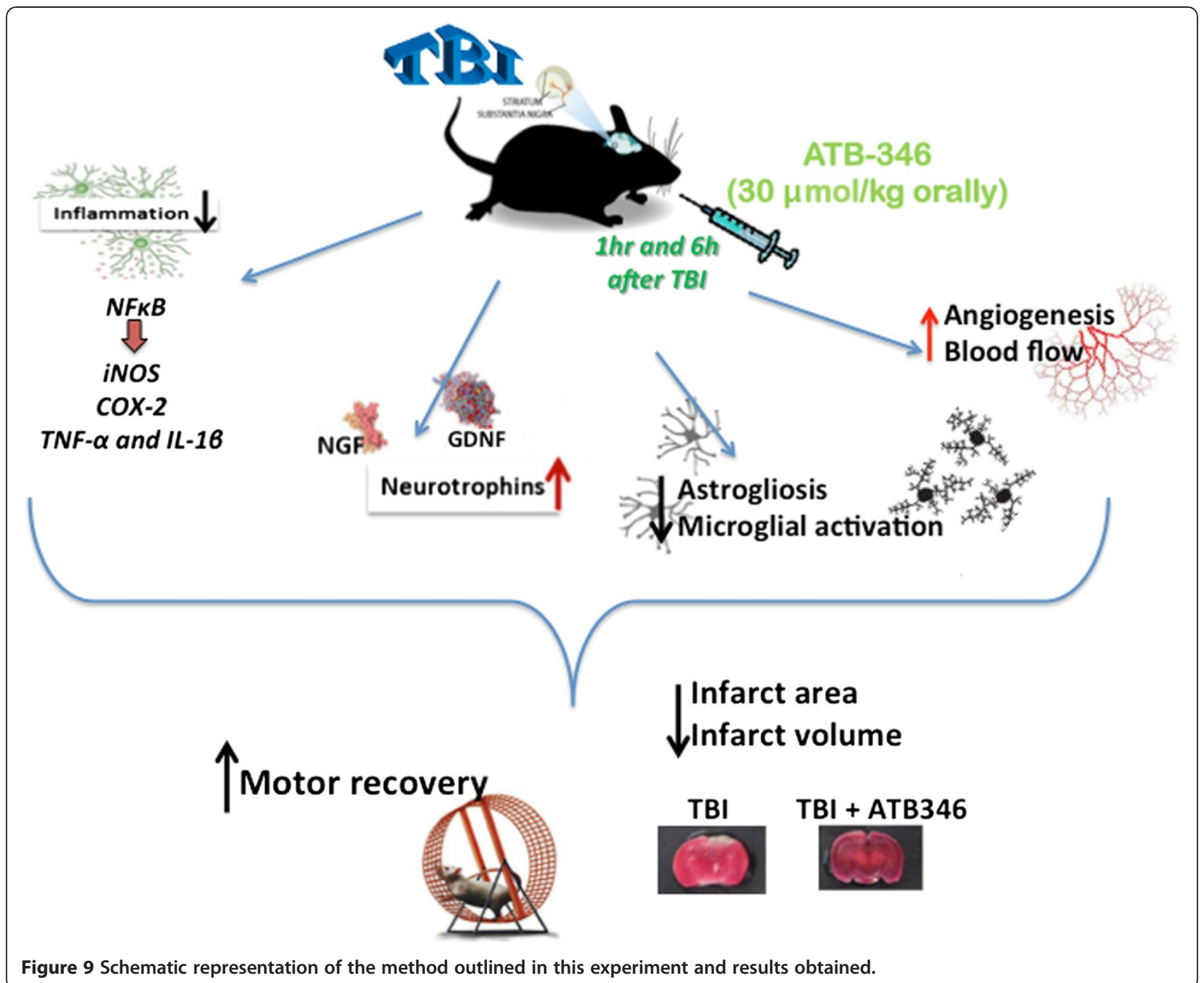

Moreover, the observation that neither naproxen nor TBZ produce the same 'restorative' effect on neurotrophic factors as seen with ATB-346 suggests that both suppression of $\mathrm{COX}$ and delivery of $\mathrm{H}^{2} \mathrm{~S}$ is required to achieve the observed effect. The properties of this compound are summarized in Figure 9. In May 2014 Antibe Therapeutics has announced the submission of a clinical trial application to Health Canada for ATB-346.

\section{Conclusions}

The need for developing new therapeutics for TBI treatment and the current lack of specific therapy for this indication underscore the importance of identification and characterization of novel neuroprotective compounds. Released- $\mathrm{H}_{2} \mathrm{~S}$ may account for the absence of deleterious gastric effects, thus making of ATB-346 a potentially useful therapeutic alternative to traditional naproxen for the management of secondary damage following CNS diseases, counteracting behavioral changes and inflammatory process.

\section{Abbreviations}

CCI: Controlled cortical impact; COX: Cyclooxygenase; EBST: Elevated Biased Swing Test; TBZ: 4-hydroxythiobenzamide; DMSO: dimethyl sulfoxide; dNTP: deoxynucleotide triphosphates; EGTA: ethylene glycol tetraacetic acid; EDTA: ethylenediaminetetraacetic acid; iNOS: inducible nitric oxide synthase; NSAIDs: Non-steroidal anti-inflammatory drugs; IL-1ß: interleukin 1 $\beta$; Iba1: ionized calcium binding adaptor molecule 1; TNFa: tumor necrosis factor a; GFAP: glial fibrillary acidic protein; NFkB: Nuclear factor kB.

Competing interests

The authors declare that they have no competing interests.

\section{Authors' contributions}

$M C$ and EE performed experiments and prepared the manuscript. $A A, R D, R S$, $M C$ and GB performed experiments and the biochemical analysis. JLW and SC planned the study, analyzed the results and prepared the manuscript. All authors read and approved the final manuscript. 


\section{Acknowledgements}

The authors would like to thank Mrs Maria Antonietta Medici for her excellent technical assistance during this study, Mr Francesco Soraci and Mr Giuseppe Mancuso for their secretarial and administrative assistance and Miss Valentina Malvagni for her editorial assistance with the manuscript.

\section{Author details}

${ }^{1}$ Department of Biological and Environmental Sciences, University of Messina, Viale Ferdinando Stagno D’Alcontres, 31-98166 Messina, Italy. ${ }^{2}$ Inflammation Research Network, University of Calgary, 3330 Hospital Drive NW, Calgary, Alberta T2N 4 N1, Canada. ${ }^{3}$ Manchester Biomedical Research Centre, Manchester Royal Infirmary, School of Medicine, University of Manchester, 29 Grafton Street Manchester, M13 9WU Manchester, UK.

Received: 4 September 2014 Accepted: 7 November 2014 Published online: 04 December 2014

\section{References}

1. Corrigan JD, Selassie AW, Orman JA: The epidemiology of traumatic brain injury. J Head Trauma Rehabil 2010, 25:72-80.

2. Rosenfeld JV, Maas Al, Bragge P, Morganti-Kossmann MC, Manley GT, Gruen RL: Early management of severe traumatic brain injury. Lancet 2012, 380:1088-1098.

3. Cernak I, Vink R, Zapple DN, Cruz Ml, Ahmed F, Chang T, Fricke ST, Faden Al: The pathobiology of moderate diffuse traumatic brain injury as identified using a new experimental model of injury in rats. Neurobiol Dis 2004, 17:29-43.

4. Anisimova IE, Salomatin EM, Pleteneva TV, Popov PI: Toxicity of non-steroid anti-inflammatory drugs. Sud Med Ekspert 2004, 47:37-41.

5. Geng B, Yang J, Qi Y, Zhao J, Pang Y, Du J, Tang C: H2S generated by heart in rat and its effects on cardiac function. Biochem Biophys Res Commun 2004, 313:362-368.

6. Zhao W, Zhang J, Lu Y, Wang R: The vasorelaxant effect of $\mathrm{H}(2) \mathrm{S}$ as a novel endogenous gaseous K(ATP) channel opener. EMBO J 2001, 20:6008-6016

7. Warenycia MW, Goodwin LR, Benishin CG, Reiffenstein RJ, Francom DM, Taylor JD, Dieken FP: Acute hydrogen sulfide poisoning. Demonstration of selective uptake of sulfide by the brainstem by measurement of brain sulfide levels. Biochem Pharmacol 1989, 38:973-981.

8. Kimura H: Hydrogen sulfide as a biological mediator. Antioxid Redox Signal 2005, 7:778-780.

9. Kimura H, Shibuya N, Kimura Y: Hydrogen sulfide is a signaling molecule and a cytoprotectant. Antioxid Redox Signal 2012, 17:45-57.

10. Wallace JL: Hydrogen sulfide-releasing anti-inflammatory drugs. Trends Pharmacol Sci 2007, 28:501-505.

11. Morgan K, Stevens EB, Shah B, Cox PJ, Dixon AK, Lee K, Pinnock RD, Hughes Richardson PJ, Mizuguchi K, Jackson AP: Beta 3: an additional auxiliary subunit of the voltage-sensitive sodium channel that modulates channel gating with distinct kinetics. Proc Natl Acad Sci U S A 2000, 97:2308-2313.

12. Campolo M, Esposito E, Ahmad A, Di Paola R, Wallace JL, Cuzzocrea S: A hydrogen sulfide-releasing cyclooxygenase inhibitor markedly accelerates recovery from experimental spinal cord injury. FASEB J 2013, 27:4489-4499.

13. Wallace JL, Caliendo G, Santagada V, Cirino G: Markedly reduced toxicity of a hydrogen sulphide-releasing derivative of naproxen (ATB-346). Br J Pharmacol 2010, 159:1236-1246.

14. Salloway S, Sperling R, Gilman S, Fox NC, Blennow K, Raskind M, Sabbagh M, Honig LS, Doody R, Van Dyck CH, Mulnard R, Barakos J, Gregg KM, Liu E, Lieberburg I, Schenk D, Black R, Grundman M, Bapineuzumab 201 Clinical Tria Investigators: A phase 2 multiple ascending dose trial of bapineuzumab in mild to moderate Alzheimer disease. Neurology 2009, 73:2061-2070.

15. Sullivan PG, Sebastian AH, Hall ED: Therapeutic window analysis of the neuroprotective effects of cyclosporine $A$ after traumatic brain injury. J Neurotrauma 2011, 28:311-318.

16. Bederson JB, Pitts LH, Germano SM, Nishimura MC, Davis RL, Bartkowski HM: Evaluation of 2,3,5-triphenyltetrazolium chloride as a stain for detection and quantification of experimental cerebral infarction in rats. Stroke 1986, 17:1304-1308.

17. Schomacher M, Muller HD, Sommer C, Schwab S, Schabitz WR: Endocannabinoids mediate neuroprotection after transient focal cerebral ischemia. Brain Res 2008, 1240:213-220.
18. Schabitz WR, Sommer C, Zoder W, Kiessling M, Schwaninger M, Schwab S: Intravenous brain-derived neurotrophic factor reduces infarct size and counterregulates Bax and $\mathrm{Bcl}-2$ expression after temporary focal cerebral ischemia. Stroke 2000, 31:2212-2217.

19. Kawai T, Akira S: Signaling to NF-kappaB by Toll-like receptors. Trends Mol Med 2007, 13:460-469.

20. Bethea JR, Castro M, Keane RW, Lee TT, Dietrich WD, Yezierski RP: Traumatic spinal cord injury induces nuclear factor-kappaB activation. J Neurosci 1998, 18:3251-3260

21. Chomczynski P, Sacchi N: Single-step method of RNA isolation by acid guanidinium thiocyanate-phenol-chloroform extraction. Anal Biochem 1987, 162:156-159.

22. Morales DM, Marklund N, Lebold D, Thompson HJ, Pitkanen A, Maxwell WL, Longhi L, Laurer H, Maegele M, Neugebauer E, Graham Dl, Stocchetti N, Mclntosh TK: Experimental models of traumatic brain injury: do we really need to build a better mousetrap? Neuroscience 2005, 136:971-989.

23. Kimura $\mathrm{Y}$, Kimura $\mathrm{H}$ : Hydrogen sulfide protects neurons from oxidative stress. FASEB J 2004, 18:1165-1167.

24. Zanardo RC, Brancaleone V, Distrutti E, Fiorucci S, Cirino G, Wallace JL: Hydrogen sulfide is an endogenous modulator of leukocyte-mediated inflammation. FASEB J 2006, 20:2118-2120.

25. Wallace JL, Caliendo G, Santagada V, Cirino G, Fiorucci S: Gastrointestinal safety and anti-inflammatory effects of a hydrogen sulfide-releasing diclofenac derivative in the rat. Gastroenterology 2007, 132:261-271.

26. Li L, Salto-Tellez M, Tan CH, Whiteman M, Moore PK: GYY4137, a novel hydrogen sulfide-releasing molecule, protects against endotoxic shock in the rat. Free Radic Biol Med 2009, 47:103-113.

27. Polhemus DJ, Lefer DJ: Emergence of hydrogen sulfide as an endogenous gaseous signaling molecule in cardiovascular disease. Circ Res 2014, 114:730-737.

28. Kimura H: Hydrogen sulfide as a neuromodulator. Mol Neurobio/ 2002, 26:13-19.

29. Blackler R, Syer S, Bolla M, Ongini E, Wallace JL: Gastrointestinal-sparing effects of novel NSAIDs in rats with compromised mucosal defence. PLoS One 2012, 7:e35196.

30. Wallace JL, Blackler RW, Chan MV, Da Silva GJ, Elsheikh W, Flannigan KL, Gamaniek I, Manko A, Wang L, Motta JP, Buret AG: Anti-inflammatory and cytoprotective actions of hydrogen sulfide: translation to therapeutics. Antioxid Redox Signal 2014.

31. Rhodes J: Peripheral immune cells in the pathology of traumatic brain injury? Curr Opin Crit Care 2011, 17:122-130

32. Liao Y, Liu P, Guo F, Zhang ZY, Zhang Z: Oxidative burst of circulating neutrophils following traumatic brain injury in human. PLoS One 2013 8:e68963.

33. DeKosky ST, Goss JR, Miller PD, Styren SD, Kochanek PM, Marion D: Upregulation of nerve growth factor following cortical trauma. Exp Neurol 1994, 130:173-177.

34. Goss JR, O'Malley ME, Zou L, Styren SD, Kochanek PM, DeKosky ST: Astrocytes are the major source of nerve growth factor upregulation following traumatic brain injury in the rat. Exp Neurol 1998, 149:301-309.

35. Mocchetti I, Wrathall JR: Neurotrophic factors in central nervous system trauma. J Neurotrauma 1995, 12:853-870.

36. Kim BT, Rao VL, Sailor KA, Bowen KK, Dempsey RJ: Protective effects of glial cell line-derived neurotrophic factor on hippocampal neurons after traumatic brain injury in rats. J Neurosurg 2001, 95:674-679.

37. Hermann DM, Kilic E, Kugler S, Isenmann S, Bahr M: Adenovirus-mediated glial cell line-derived neurotrophic factor (GDNF) expression protects against subsequent cortical cold injury in rats. Neurobiol Dis 2001, 8:964-973.

38. Shore PM, Jackson EK, Wisniewski SR, Clark RS, Adelson PD, Kochanek PM: Vascular endothelial growth factor is increased in cerebrospinal fluid after traumatic brain injury in infants and children. Neurosurgery 2004, 54:605-611. discussion 611-602.

39. Pedersen MO, Larsen A, Pedersen DS, Stoltenberg M, Penkova M: Metallic gold treatment reduces proliferation of inflammatory cells, increases expression of VEGF and FGF, and stimulates cell proliferation in the subventricular zone following experimental traumatic brain injury. Histol Histopathol 2009, 24:573-586.

40. Cui X, Chopp M, Zacharek A, Ning R, Ding X, Roberts C, Chen J: Endothelial nitric oxide synthase regulates white matter changes via the BDNF/TrkB pathway after stroke in mice. PLoS One 2013, 8:e80358. 
41. Lundblad C, Grande PO, Bentzer P: Hemodynamic and histological effects of traumatic brain injury in eNOS-deficient mice. J Neurotrauma 2009, 26:1953-1962

42. Hall ED, Wang JA, Miller DM: Relationship of nitric oxide synthase induction to peroxynitrite-mediated oxidative damage during the first week after experimental traumatic brain injury. Exp Neurol 2012, 238:176-182.

43. Kondo K, Bhushan S, King AL, Prabhu SD, Hamid T, Koenig S, Murohara T, Predmore BL, Gojon G Sr, Gojon G Jr, Wang R, Karusula N, Nicholson CK, Calvert JW, Lefer DJ: $H(2) S$ protects against pressure overload-induced heart failure via upregulation of endothelial nitric oxide synthase. Circulation 2013, 127:1116-1127.

44. Kram L, Grambow E, Mueller-Graf F, Sorg H, Vollmar B: The anti-thrombotic effect of hydrogen sulfide is partly mediated by an upregulation of nitric oxide synthases. Thromb Res 2013, 132:e112-e117.

45. Altaany Z, Yang G, Wang R: Crosstalk between hydrogen sulfide and nitric oxide in endothelial cells. J Cell Mol Med 2013, 17:879-888.

46. Kamat PK, Kalani A, Givvimani S, Sathnur PB, Tyagi SC, Tyagi N: Hydrogen sulfide attenuates neurodegeneration and neurovascular dysfunction induced by intracerebral-administered homocysteine in mice. Neuroscience 2013, 252:302-319.

doi:10.1186/s12974-014-0196-1

Cite this article as: Campolo et al:: Hydrogen sulfide-releasing cyclooxygenase inhibitor ATB-346 enhances motor function and reduces cortical lesion volume following traumatic brain injury in mice. Journal of Neuroinflammation 2014 11:196.

\section{Submit your next manuscript to BioMed Central and take full advantage of:}

- Convenient online submission

- Thorough peer review

- No space constraints or color figure charges

- Immediate publication on acceptance

- Inclusion in PubMed, CAS, Scopus and Google Scholar

- Research which is freely available for redistribution 